\title{
Muscle
}

\section{The sliding filament at 50}

\author{
"In spite of the numerous \\ investigations which have been \\ made into the changes of the \\ striations of muscle when it \\ contracts, there is little agreement \\ at the present day on either the \\ nature or the significance of these \\ changes." Thus started the first of \\ two independent, ground-breaking \\ papers $^{1,2}$, published together in \\ Nature on 22 May 1954, which \\ brought general agreement about \\ those changes. The papers showed \\ that muscle shortens by relative \\ sliding between two sets of \\ subcellular filaments containing \\ the proteins myosin and actin. This \\ was the first demonstration that \\ a cell's primary function could \\ be understood in terms of a \\ fundamental interaction between \\ two protein molecules. \\ In the first of the papers ${ }^{1}$, \\ Andrew Huxley and Rolf Niedergerke \\ reported measurements of the \\ optically dense 'A-bands' in \\ intact fibres from striated (skeletal) \\ muscle. Using a novel interference \\ microscope, the authors \\ demonstrated that the width of \\ the A-bands remains constant \\ during contraction. To account \\ for their observations, they \\ suggested a 'sliding-filament' model
}

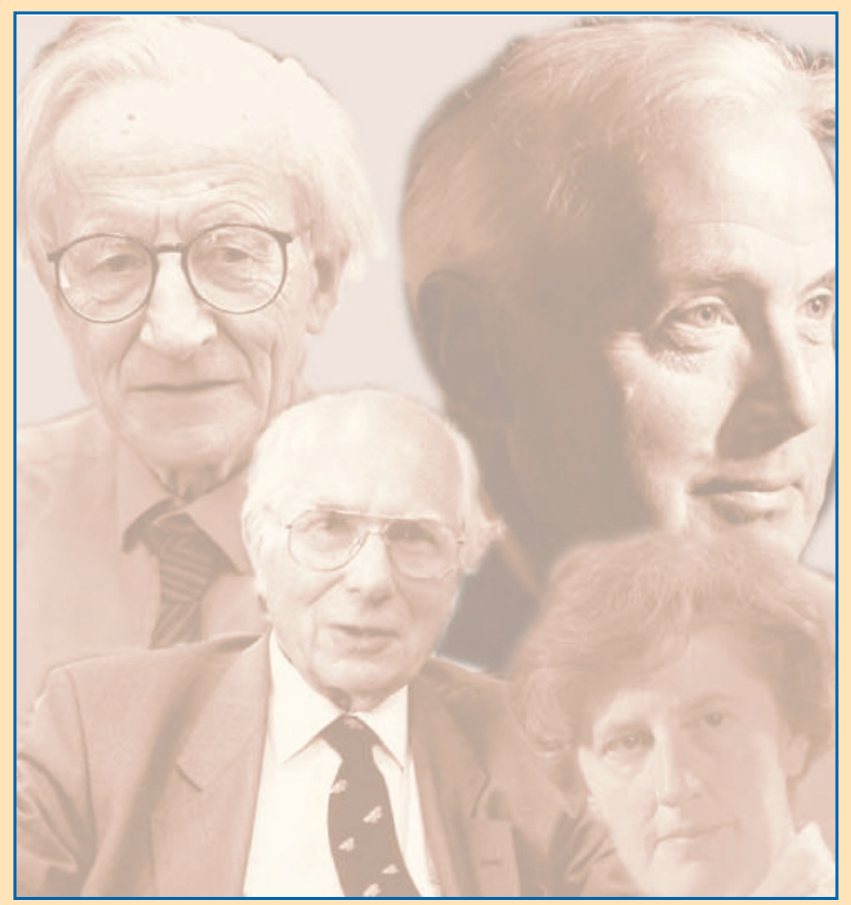

in which myosin filaments run the length of the A-band and actin filaments slide into this band when muscle shortens.

In the second paper ${ }^{2}$, Hugh Huxley (no relation to Andrew) and Jean Hanson described their light-microscope investigations of isolated myofibrils from striated muscle; myofibrils are subfibres of muscle that are thinner and more suitable for light microscopy. Huxley and Hanson independently established the constancy of the A-band width and also invoked a sliding-filament model to explain their data. They also extracted myosin from the
A-bands and demonstrated the role of ATP hydrolysis in powering the contraction-relaxation cycle of muscle.

Pictured here are the four protagonists. Clockwise from bottom left: Andrew Huxley, Rolf Niedergerke, Hugh Huxley and Jean Hanson.

The impact of the early work, and later developments in understanding the molecular mechanisms of what have since become known as motor proteins, are the subject of two meetings ${ }^{3,4}$ to be held in London next week. The two classic papers are reproduced in full in a special web focus ${ }^{5}$. The web focus also includes selected Nature publications that subsequently advanced our understanding of the molecular basis of muscle contraction and its bearing on an intriguing issue - the biological conversion of chemical energy into mechanical work. Maxine Clarke

1. Huxley, A. F. \& Niedergerke, R. Nature 173, 971-973 (1954).

2. Huxley, H. E. \& Hanson, J. Nature 173, 973-976 (1954)

3. www.royalsoc.ac.uk/events/ discussion meetings/level_2/may04.html

4. www.kcl.ac.uk/175/events/event0520.html

5. www.nature.com/nature/focus/ slidingfilaments blood pressure (hypertension) through the activation of the RAS. A similar mechanism could perhaps account for, or contribute significantly to, the renin-mediated hypertension that is associated with constriction of the renal artery by cholesterol plaques, as occurs in diabetes, kidney disease and other conditions. If the TCA receptors are indeed involved, however, then receptor blockers might be expected to inhibit kidney renin secretion and relieve hypertension.

And there are further possible medical implications. The concentrations of TCAcycle intermediates depend to a certain extent on the state of the enzymes that are responsible for their turnover. Succinate levels, for instance, might be increased when the mitochondrial activity of the complex containing succinate dehydrogenase and its activator, coenzyme $\mathrm{Q}_{10}\left(\mathrm{CoQ}_{10}\right)$, is low. Low concentrations of $\mathrm{CoQ}_{10}$ occur after heart failure and hypertension. Oral administration of this coenzyme improves heart function in some patients ${ }^{10}$, and some patients with hypertension can discontinue antihypertensive medications after taking $\mathrm{CoQ}_{10}$ (ref. 11). It would be interesting to know whether these effects are linked to a decrease in extracellular concentrations of succinate and hence in the activation of the RAS. Another observation is that some drugs use succinate as a salt; could this be having an effect in some patients?

TCA-cycle intermediates such as $\alpha$ ketoglutarate and succinate have also been shown to reduce the mitochondrial injury, in kidneys and other tissues, that is caused by successive decreases and increases in oxygen concentrations ${ }^{12}$; such intermediates are also used in kidney (and liver) preservation solutions for organ transplantation ${ }^{13}$. What role, if any, might the TCA receptors have here? And might these receptors function in tissues other than kidneys? The complete RAS is expressed in many tissues, including the placenta, brain, heart, gonads and pancreas $^{14,15}$. Intriguingly, the placenta also expresses GPR99 (ref.7), and disturbances in placental RAS activity can reduce placental blood flow in pregnancy, often with severe complications $^{14}$.

Many aspects of the function of the newly identified TCA receptors clearly remain to be determined. Similar exciting discoveries are likely to come as more and more orphan receptors find their homes in the GPCR family.

Steven C. Hebert is in the Department of Cellular and Molecular Physiology, Yale University School of Medicine, 333 Cedar Street, New Haven,

Connecticut 06520-8026, USA.

e-mail: steven.hebert@yale.edu

1. Barnett, J. A. Yeast 20, 1015-1044 (2003).

2. Eng, C., Kiuru, M., Fernandez, M. J. \& Aaltonen, L. A. Nature Rev. Cancer 3, 193-202 (2003).

3. He, W. et al. Nature 429, 188-193 (2004).

4. Horn, F. et al. Nucleic Acids Res. 31, 294-297 (2003).

5. Pierce, K. L., Premont, R. T. \& Lefkowitz, R. J. Nature Rev. Mol. Cell Biol. 3, 639-650 (2002).

6. Joost, P. \& Methner, A. Genome Biol. 3, RESEARCH0063 (2002)

7. Wittenberger, T. et al. BioMed Central Genomics 3, 17 (2002).

8. Wittenberger, T., Schaller, H. C. \& Hellebrand, S. J. Mol. Biol. 307, 799-813 (2001).

9. Baumbach, L., Leyssac, P. P. \& Skinner, S. L. J. Physiol. (Lond.) 258, 243-256 (1976).

10. Jeejeebhoy, F. et al. Am. Heart J. 143, 1092-1100 (2002).

11. Hodgson, J. M., Watts, G. F., Playford, D. A., Burke, V. \& Croft, K. D. Eur. J. Clin. Nutr. 56, 1137-1142 (2002)

12. Feldkamp, T. et al. Am. J. Physiol. Renal Physiol. 286, F749-F759 (2004).

13. St Peter, S. D., Imber, C. J. \& Friend, P. J. Lancet 359, 604-613 (2002)

14. Nielsen, A. H., Schauser, K. H. \& Poulsen, K. Placenta 21, 468-477 (2000).

15. Lavoie, J. L. \& Sigmund, C. D. Endocrinology 144, 2179-2183 (2003). 